\title{
A Rare Case Report: Malignant Vulvar Melanoma
}

\author{
Qurrat ul Ain ${ }^{1} \cdot$ Bharati Rao ${ }^{1}$
}

Received: 1 November 2019 / Accepted: 6 January 2020/Published online: 17 January 2020

(C) The Author(s) 2020

\begin{abstract}
Cancer of the vulva is not a common disease. It accounts for approximately $4 \%$ of cancers in the female reproductive organs and $0.6 \%$ of all cancers in women. Malignant melanomas of the vulva are rare tumors located in areas of the body not exposed to ultraviolet radiation. Although vulvar melanomas account for less than $1 \%$ of all melanomas, they are the second most common type of vulvar malignancy accounting for around $10 \%$ of all malignant tumors involving the vulva. Presentation is typically a decade later than cutaneous melanoma with a tendency to late metastases and poorer prognosis. Given their rarity, the treatment paradigm is less clearly defined and largely extrapolated from that of cutaneous melanomas. A case of Mrs. Y, 70 years old, P3L1 presented with complaints of swelling in the labial region for two and a half months, associated with severe itching, was reported. She also had C/O white discharge PV for 2 months, which was nonfoul smelling and not blood-stained; on examination, her abdomen was soft and non-tender. A local examination found $2 \times 3 \mathrm{~cm}$ growth arising from labia minora, irregular surface, and hyperpigmented lesion with white patches and ulcerated surface. Left inguinal lymph nodes were palpable. Per speculum examination revealed pigmented lesions over the anterior vaginal wall, anterior and posterior lip of cervix, cervix and vagina healthy. Excisional biopsy, fractional curettage, and FNAC were done. Histopathology of the specimen showed the diagnosis of nodular melanoma (tumorigenic melanoma), Clark's level IV. Cervical biopsy showed the features of chronic cervicitis. FNAC showed the features of metastatic malignant melanoma.
\end{abstract}

Keywords Rare vulval carcinoma $\cdot$ Melanoma $\cdot$ Malignant

\section{Introduction}

Cancer of the vulva is a rare neoplasm, accounting for less than $1 \%$ of malignant neoplasms among women. Malignant melanomas of the vulva are mucocutaneous melanocytic tumors located in areas of the body not exposed to ultraviolet radiation. Although vulvar melanomas account for less than $1 \%$ of all melanomas, they are the second most common type of vulvar malignancy accounting for around $10 \%$ of all malignant tumors involving the vulva [1].

Although rare, gynecologists and dermatologists may relatively often encounter this neoplasm, particularly within referral centers. Given that the lesion size is a determinant for the prognosis, early detection of the tumor is of vital importance. Presentation is typically a decade

Qurrat ul Ain

qurrat.07@gmail.com

1 Department of OBG, KMC Mangalore, Mangalore, India later than cutaneous melanoma with a tendency to late metastases and poor prognosis.

Given their rarity, the treatment paradigm is less clearly defined and largely extrapolated from that of cutaneous melanomas.

\section{Case Report}

Mrs. Y, 70 years old, P3L1 postmenopausal lady hailing from Shimoga, presented with complaints of swelling in the labial region for two and a half months, associated with severe itching.

She also complained of white discharge per vagina for 2 months, which was non-foul smelling and not bloodstained. But she does not have a history of postmenopausal bleeding, loss of weight/appetite, and bowel/bladder complaints.

No significant medical/surgical past history. 


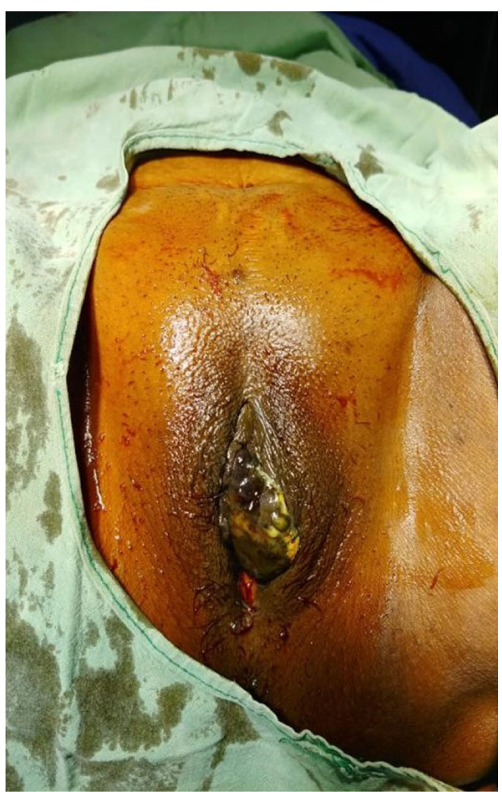

Fig. 1 Hyperpigmented growth over labia minora

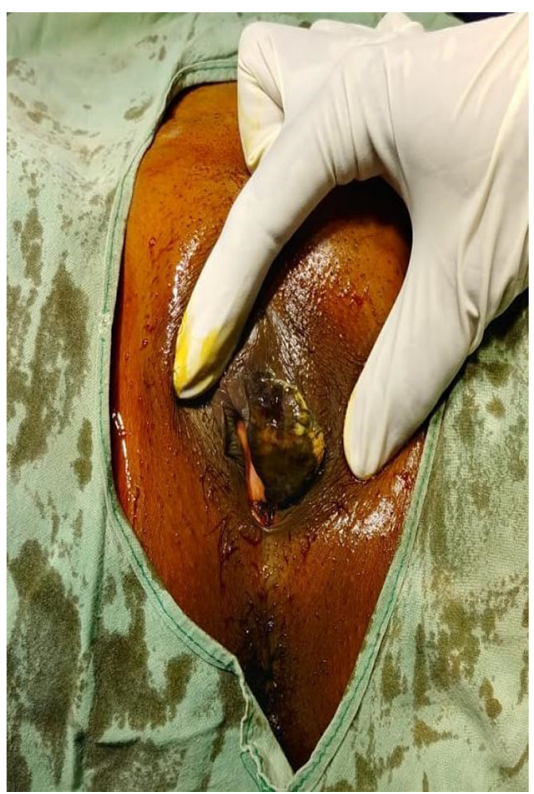

Fig. 2 Hyperpigmented growth over labia minora with white patches and ulcerated surface

On examination, vitals were found to be within normal limits.

P/A soft, non-tender, no organomegaly.

L/E $2 \times 3 \mathrm{~cm}$ growth arising from labia minora, irregular surface, and hyperpigmented lesion with white patches and ulcerated surface (Figs. 1 and 2).

Per speculum examination pigmented lesions over the anterior vaginal wall and the anterior and posterior lip of cervix (Figs. 3 and 4).

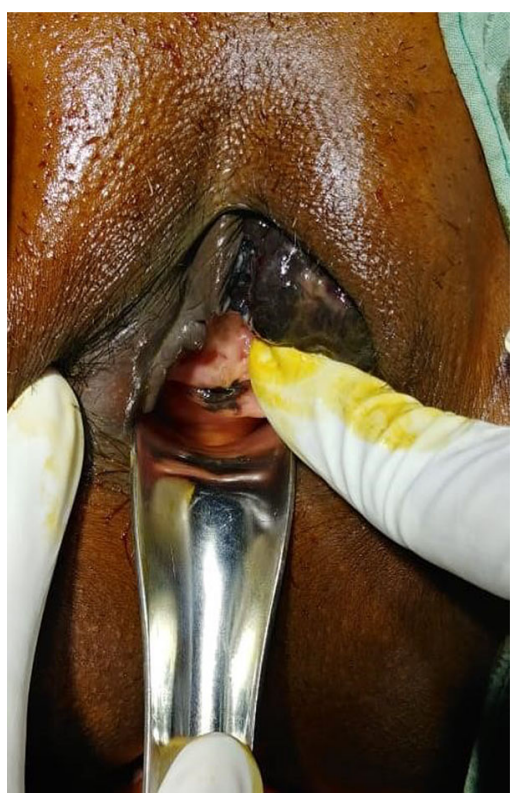

Fig. 3 Pigmented lesions involving anterior vaginal wall

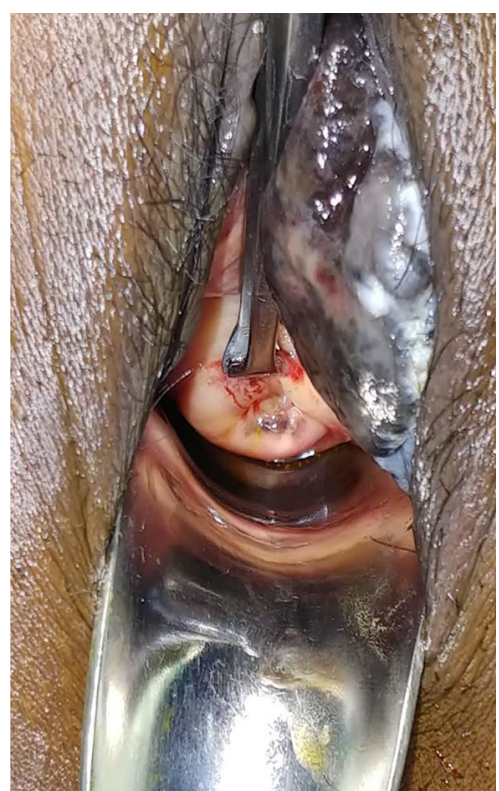

Fig. 4 Pigmented lesions over cervical lip

Per vaginal examination uterus normal size, $\mathrm{B} / \mathrm{L}$ fornices free, no forniceal tenderness.

Left inguinal lymph nodes palpable.

\section{Management}

Routine blood investigations done were within normal limits.

Pap smear-no evidence of intraepithelial lesion/malignancy. 


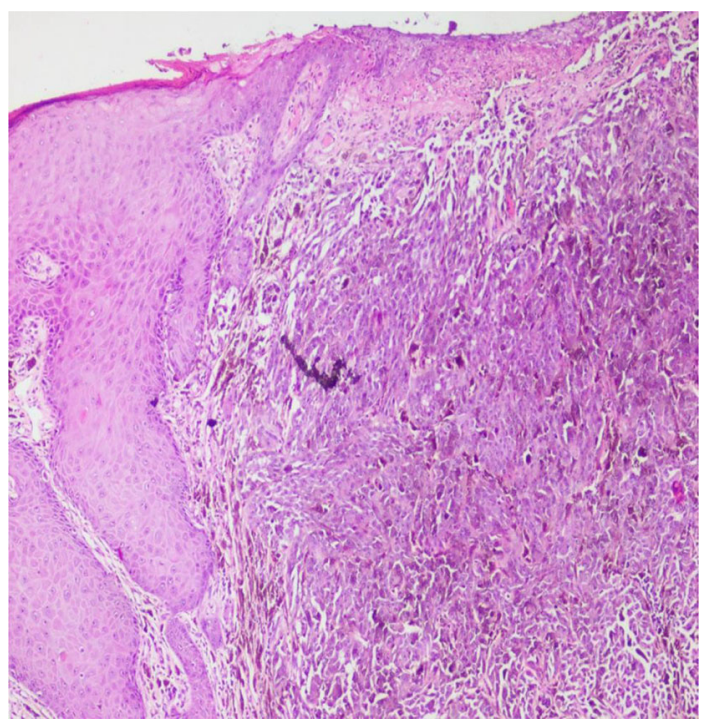

Fig. 5 HPE showing extensive ulceration of skin with underlying tumor cells

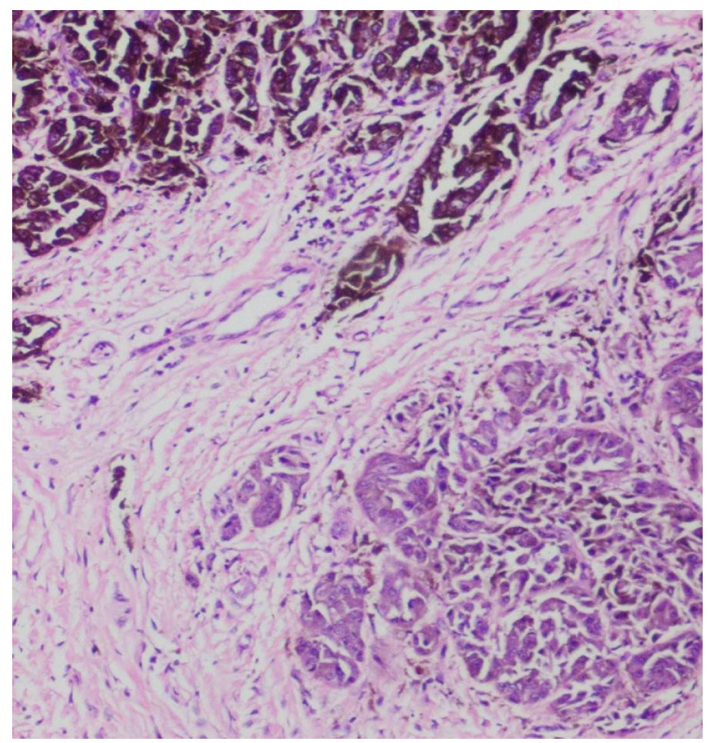

Fig. 6 Melanin seen as a fine granular intra-cytoplasmic pigment

Excision biopsy + fractional curettage done and sent for HPE.

Histopathology of the specimen revealed the diagnosis of nodular melanoma (tumorigenic melanoma), Clark's level IV (Figs. 5 and 6).

Cervical biopsy shows the features of chronic cervicitis.

FNAC of the lymph node showed metastatic malignant melanoma (Figs. 7 and 8).

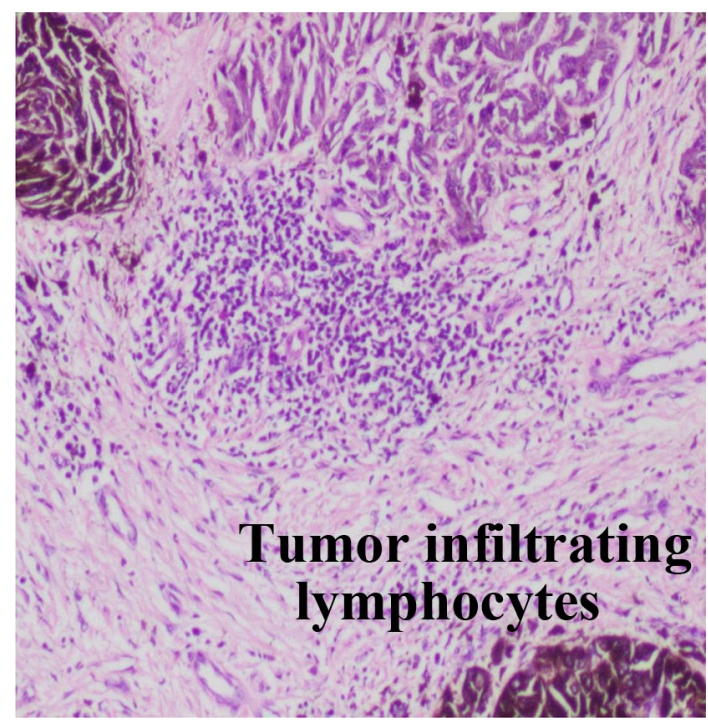

Fig. 7 FNAC of left inguinal lymph node showing tumor-infiltrating lymphocytes

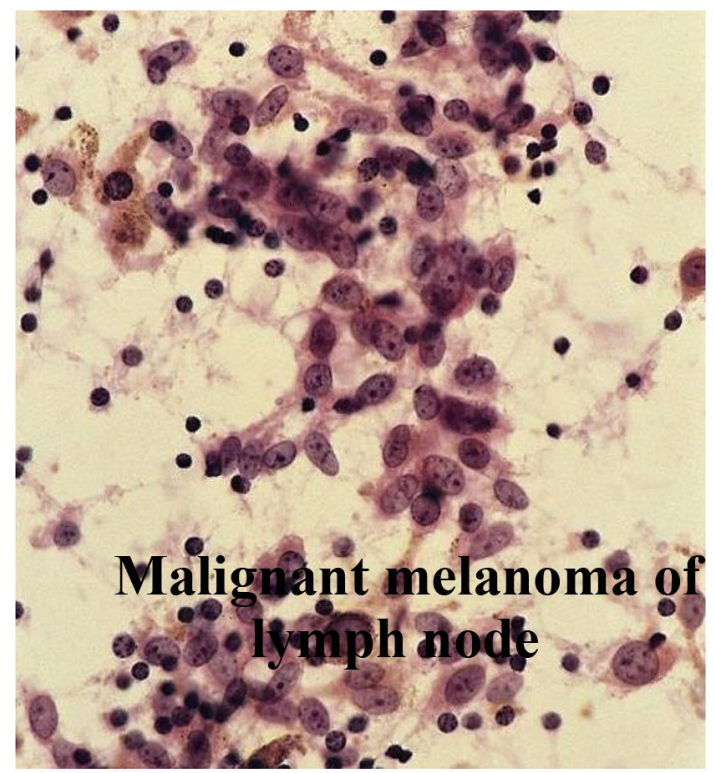

Fig. 8 FNAC showing melanocytic cells involving a lymph node

\section{Discussion}

Malignant melanomas involving the female genital tract are rare; the ratio of its manifestation when compared with cutaneous melanoma is $1: 71$. It occurs predominantly in postmenopausal women, contrary to melanomas at other sites which occur before 45 years [2].

The etiology of vulvar melanoma is poorly understood but found to arise de novo on the clitoris or labia minora; it can also develop within preexisting junctional or compound nevi [3]. Although certain signs and symptoms may strongly suggest vulvar cancer, the only way to be certain 
is a biopsy. Clinically, patients most commonly present with asymptomatic pigmented lesion, the usual clinical form is superficial spreading melanoma, the much lesser common form is nodular which is more aggressive and has a poorer prognosis, and the histologic types, in order of incidence, are superficial spreading (40-58\%), mucosal lentiginous (27-57\%), nodular (22-28\%), and unclassified (12-16\%).

In the past, vulvar melanoma was grouped with other vulvar cancers and staged with the International Federation of Gynaecological and Obstetric system, which, though appropriate for SCC, does not reflect prognosis for vulvar melanoma. The Breslow, Clark, and Chung systems of staging have a better correlation. The Chung staging is primarily based on Clark's level of tumor invasion.

Complete excision of the lesion is indicated in cases with a suspected diagnosis. Currently, surgery still remains the best option albeit without the need for radical procedures. Radical vulvectomy with bilateral lymphadenectomy is becoming a questionable and obsolete treatment approach. Alternatively, wide local excision with a $1-\mathrm{cm}$ surgical margin is recommended for lesions with a depth of less than $1 \mathrm{~mm}$ and en bloc resection for deeper lesions, with a safety margin of $2-3 \mathrm{~cm}$ and regional lymphadenectomy (inguinal-femoral). Adjuvant treatment with immunotherapy, chemotherapy, and radiotherapy may be recommended in specific cases and for local recurrences and distant metastases.

The main prognostic factors include tumor size, depth of invasion, presence of ulceration, and occurrence of lymph node metastases. In addition, the patient's age and tumor stage also appear to be critical factors in the survival of women with vulvar melanoma.

The behavior of primary malignant vulvar and extragenital cutaneous melanomas appears to be similar. However, some studies have shown that the general prognosis of patients with vulvar melanoma is worse than that of women with extragenital melanoma and SCC of the vulva, showing a greater tendency for local and distal recurrence.

\section{Conclusion}

In conclusion, malignant vulvar melanoma is a rare, extremely aggressive tumor with an overall poor prognosis (5-year survival rate $<10 \%$ ) [4]. A nonstandardized approach to vulvar melanoma characterized by the use of multiple staging systems and outdated prognostic parameters exists in the literature. The data on vulvar melanoma consist of almost entirely of case studies and small retrospective series. Standardized and systematic documentation of clinical and histologic findings is needed to advance knowledge and facilitate the grouping of cases from different institutions for more statistically powerful conclusions.

\section{Compliance with ethical standards}

Conflict of interest The authors declare that they have no conflict of interest.

Open Access This article is licensed under a Creative Commons Attribution 4.0 International License, which permits use, sharing, adaptation, distribution and reproduction in any medium or format, as long as you give appropriate credit to the original author(s) and the source, provide a link to the Creative Commons licence, and indicate if changes were made. The images or other third party material in this article are included in the article's Creative Commons licence, unless indicated otherwise in a credit line to the material. If material is not included in the article's Creative Commons licence and your intended use is not permitted by statutory regulation or exceeds the permitted use, you will need to obtain permission directly from the copyright holder. To view a copy of this licence, visit http://creativecommons. org/licenses/by/4.0/.

\section{References}

1. Irvin WP Jr, Bliss SA, Rice LW, Taylor PT Jr, Andersen WA. Malignant melanoma of the vagina and locoregional control: radical surgery revisited. Gynecol Oncol. 1998;71(3):476-80.

2. Miner TJ, Delgado R, Zeisler J, Busam K, Alektiar K, Barakat R, Poynor E. Primary vaginal melanoma: a critical analysis of therapy. Ann Surg Oncol. 2004;11(1):34-9.

3. Hu DN, Yu GP, McCormick SA. Population-based incidence of vulvar and vaginal melanoma in various races and ethnic groups with comparisons to other site-specific melanomas. Melanoma Res. 2010;20:153-8.

4. Greggi S, Losito S, Pisano C, Desicato S, Scaffa C. Malignant melanoma of the vagina: report of two cases and review of the literature. Int Surg. 2010;95(2):120-5.

Publisher's Note Springer Nature remains neutral with regard to jurisdictional claims in published maps and institutional affiliations. 